\title{
Synergetic approach in the design of architectural systems for harsh climatic conditions
}

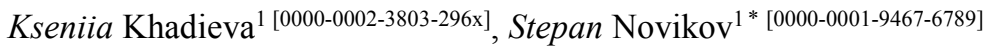 \\ ${ }^{1}$ Kazan State University of Architecture and Engineering, 420043, Zelenaya st., Kazan, Russia
}

\begin{abstract}
Architecture is characterized by a correction of design approaches that take into account new discoveries. Changing scientific paradigm also influences this process by introducing extra details into the architectural objects workflows. The synergistic paradigm that influences mostly appears in the tendency to create architecture that meets the ideal standards of sustainable design, capable design which is of selfdevelopment and self-regulation. A unique feature of the synergistic paradigm that can fundamentally change the approach to design is its relation to the evolutionary process. According to this concept, evolution in its path passes through points of bifuciation - special states of instability when possible ways of further development are clear and it becomes possible for us to choose and follow one of them. This approach takes into account changing data and corrects decisions during the process. This is especially relevant when designing architectural objects for harsh climate conditions, as additional difficulties may arise in the process of construction and operation, and the unexpectedly arising issues, which may unanticipated arise itself during the usage of the object and can have a disastrous effects on it.
\end{abstract}

Keywords. Synergetic approach, architectural systems, Arctic architecture, fractal structures, sustainability.

\section{Introduction}

Today, due to the accelerated pace of globalization and population growth, humanity is increasingly faced with the issue of expanding oikumena and developing new habitats. For many millennia, the population of our planet has increased according to hyperbolic law. According to statistical forecasts, the population of the Earth will reach 9 billion people in the period 2043-2050. This phenomenon requires an expansion of the «ecological niche» of the existence of humanity and the development of a new environment, or, it seems, several such environments. These environments include the polar regions.

The gradual transition to a new scientific paradigm, which is based on a synergistic approach, is gaining an increasing influence on architecture and, of course, is increasingly penetrating into the field of design. From the point of view of synergy, any architectural

${ }^{*}$ Corresponding author: to-stepa@mail.ru 
space is, first of all, a system that constantly changes from any external or internal influence, which is similar to the behaviour of a living organism. All this is clearly reflected in the tendency to create objects that meet the ideals of sustainable development. Against the background of these ideas, they are increasingly heard about the architecture of selfdeveloping and self-regulating, living like an organism in which life processes are stabilized [1-2].

At the same time, it must be borne in mind that the city is an ecological system, which includes two constituent parts-subsystems - natural and anthropogenic - the essence of the interaction of which is to maintain balance and harmonious coexistence. At the same time, the question of the possibilities of self-regulation of such a system, from the object level to urban planning, remains dialectical. Should we focus on creating a smart self-developing architecture that will strive for a stable system?

The process of evolution develops in such a way that at certain stages it passes through the so-called bifurciation points ${ }^{1}$, which, in fact, are moments of instability, during which possible options for further development appear and the path is chosen, along which, in the end, evolution follows (Fig. 1). The principle of evolutionary development is the same for history, and for science, and, in particular, for architecture. The period of stability and equilibrium is always followed by a period of instability, this is a prerequisite for the evolutionary process [3].

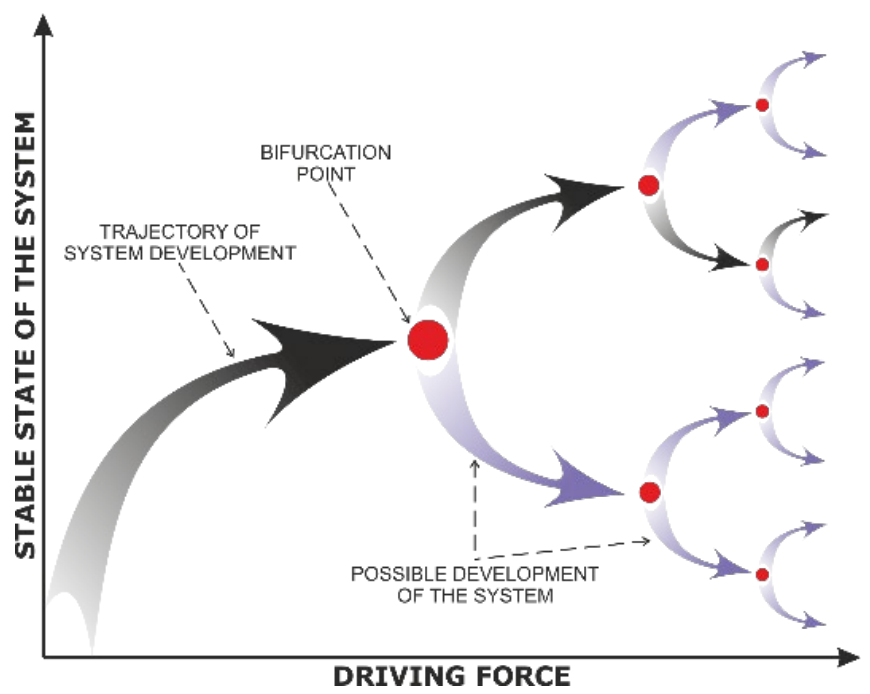

Fig. 1. Forming a field of development paths.

Will an architectural object created with the idea of stationary stability embedded in it be able to be used for a long and effective time within the framework of a rapid change in the world? Or should the new architecture lay down certain stages of development, when their further development is determined, based on probabilities, is there a choice? In synergy, there is the term «field of development paths» [4]. In architecture, an illustration of this phenomenon to some extent can be called the conceptual design process, when different options are proposed for what an architectural object can be.

\footnotetext{
${ }^{1}$ In synergy, bifurcation point is a critical state of the system in which the system becomes unstable relative to fluctuations and uncertainty arises: will the state of the system become chaotic or will it switch to a new, more differentiated and high level of order.
} 
The variability of the development of an architectural object illustrates well the modularity method. The very idea of modular architecture initially has a resource for transformation and growth. It should be noted that a number of conditions can be distinguished in which the use of the module as a fundamental architectural unit is more than justified. Among them if architecture is in extreme conditions, in particular, the architecture of the Arctic.

\section{Materials and methods}

The study is based on a comprehensive literature and bibliographic analysis of the existing design and conceptual experience of construction in the Arctic and Antarctic conditions, taking into account the principles of synergy and includes the following methods:

- generalization of foreign and domestic design experience in harsh climate conditions, study and systematization of theoretical and literary sources, which made it possible to conduct a graphical analysis of implemented and conceptual architectural objects for polar territories;

- identification of general patterns related to the possibility of using the properties of fractal structures in the architecture of polar latitudes;

- study of all-Russian and international competitive materials and projects, including Arctic Perspective, Architectural Image of Russia, Archiprix, competitions for the development of year-round Halley VI stations.

The materials for the study were research on synergy, specialized literature on the architecture of polar regions, design materials.

\section{Results and Discussion}

\subsection{Design features in severe climatic conditions}

The processes of globalization and urbanization for the modern world have become a catalyst for the search for new behavioural models of human life. However, each of these models has its own uniqueness and requires a special approach. If in mild climatic conditions, with an unsuccessful design solution, the main risks are mainly associated with the economic factor and falling into the environmental context, then in the conditions of the polar regions operational risks also increase significantly: the safety of the operation of the facility and the speed of development of the territory, which, among other things, pulls an increase in economic risks. At the same time, the International Community has long recognized the value of the polar regions as a kind of «reserve zone» of importance for the future of civilization of the Earth [5-8].

According to the definition of L. Gumilev, the nature of the traditional forms of the material world of the North and the Arctic peoples historically organically fit into the landscape, being based on the principle of feedback, which made it possible to reduce the influence on nature and the surrounding world. For this reason, various interpretations of the principles of shaping a traditional dwelling are relevant in shifting to modern realities. At the present stage, there is a search for architectural forms that are adequate precisely to polar conditions. The main trends are small forms, mobility, autonomy. These are domed houses, experimental houses of heliotecture, and mobile forms of dwellings. However, so far such projects of the new Arctic architecture are isolated, or even artisanal. [9-13]

The territory of the Arctic and Antarctic is characterized by instability, this is an integral feature of Arctic nature. Due to the abundance of natural risks, the architecture must be ready for rapid transformation. In this regard, laying long-term projects that are not 
designed for possible transformations in the process of implementation is initially unprofitable, since even one breakthrough can change a lot. An architecture originally programmed for growth, development and change, for which, depending on the associated conditions and factors, we can determine the necessary degree of development of the system for a given moment, seems to have significant potential [14].

In general, it can be assumed that modern architectural systems for harsh climatic conditions, such as, for example, polar, should be formed, focusing on a number of principles (Fig. 2). Such an architecture should be compact, strive for self-sufficiency and a certain level of closeness of the spatial structure, it should form a comfortable microclimate, and maintain the maximum possible level of environmental friendliness.

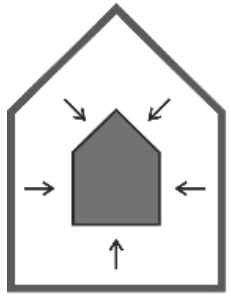

COMPACT

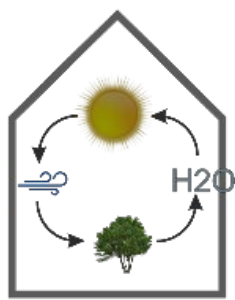

ARTIFICIAL

CLIMATE

SYSTEMS

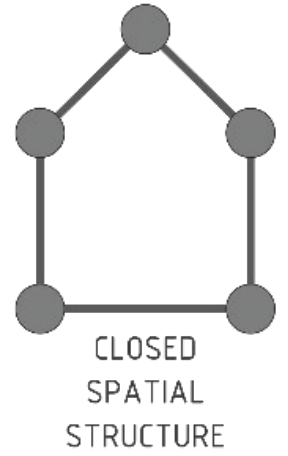

Fig. 2. Resource efficient design principles for polar conditions.

\subsection{Use of fractal structures in polar architecture}

Fractal structures can be considered as one of the potentially successful design options. A feature of the use of fractals in architecture is that the use of fractal structures is possible at all levels of the organization of the architectural environment [15].

In his article on the use of fractal models in architecture, V.N. Babich identified the following properties of fractal structures [16-17]:

- Self-similarity (hierarchical principle of organization);

- Ability to develop (principle of continuity of shaping);

- Fractional metric dimension (principle of measure singularity);

- The principle of boundary uncertainty (blur, fuzzy contours);

- The principle of dynamic chaos (a phenomenon in which the behaviour of a nonlinear system looks random, although it obeys deterministic laws).

Within the framework of architectural science, fractal properties such as self-similarity and developmental ability gain leading importance. Self-similarity means that each, a single part of the fractal, repeats in its development, the development of the entire fractal as a whole and is reproduced in different scaling without visible changes. This fractal property 
is pronounced when using basic modules. Depending on the size of the architectural system in a particular territory and the functional purpose of the module, it can have different sizes, accordingly the complex can consist of a single module, either of several connected equivalent or different-sized modules that form a more complex system (Fig. 3).
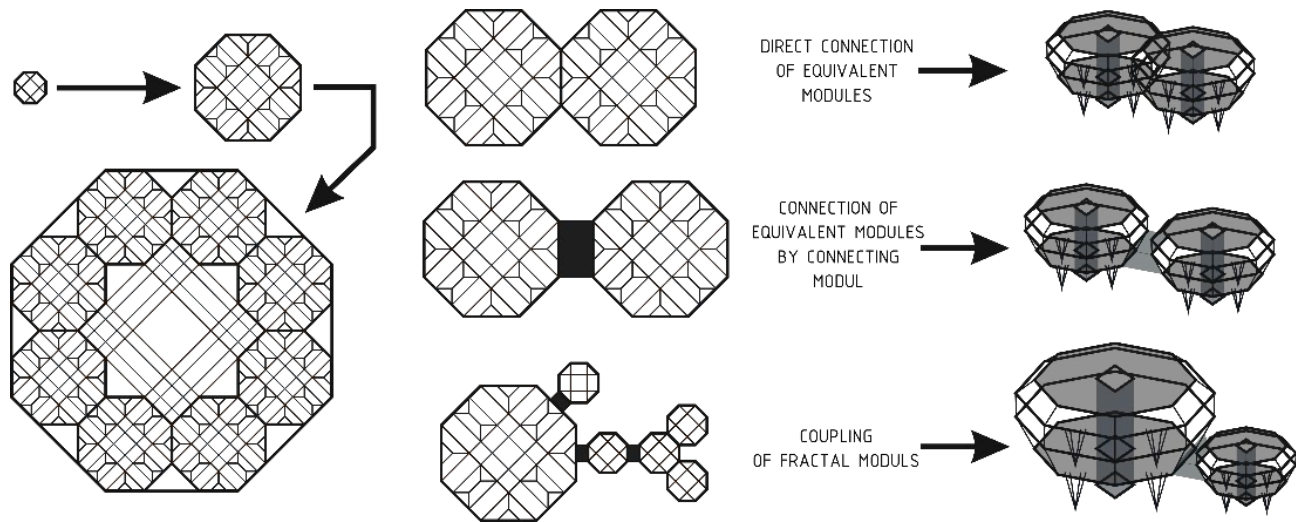

Fig. 3. An example of using a fractal structure in an urban planning system.

Another important fractal property is the ability to develop [18-21]. It is assumed that the system is able to grow and evolve, while the process of evolution of the object is laid down as dialectical.

Of particular interest is the implementation in architecture of the principle of dynamic chaos. In his article «Philosophy of Instability», I. Prigozhin expresses the idea that instability can be a condition for stable and dynamic development. In his opinion, only systems in a state of instability have the ability to develop and spontaneous organization, «since only in states far from stability complexity arises».

As part of this statement, we return to the fact that the process of evolution of architecture in harsh climate conditions develops, at certain stages passing through points of bifuciation. And it is at these points of instability that the potential lies, demonstrating the options for further development, and the path is chosen, along which, in the end, evolution follows further [22-24].

\section{Conclusions}

As a result, it can be concluded that at certain points in the development of the integrated structure, it is necessary to build analytical models of the further life cycle of the architectural object, on the basis of which the most important aspects can be distinguished in the near future, to understand whether there is a need for system adjustments, how it should be changed and whether it is necessary to join new modules and introduce modern innovations [25]. This approach allows you to monitor the operation of an object, analyze its life cycle in dynamics and affect it. This is of particular importance in an environment where the capacity and capabilities of the Territory are likely to change, new functions may need to be introduced and, accordingly, the architectural structure may need to be modified and updated [26-27].

This approach is possible when forming concepts based on the properties of fractal systems: self-similarity; capacities for development; fractional metric dimension; the principle of boundary uncertainty; and following the principle of dynamic chaos. 


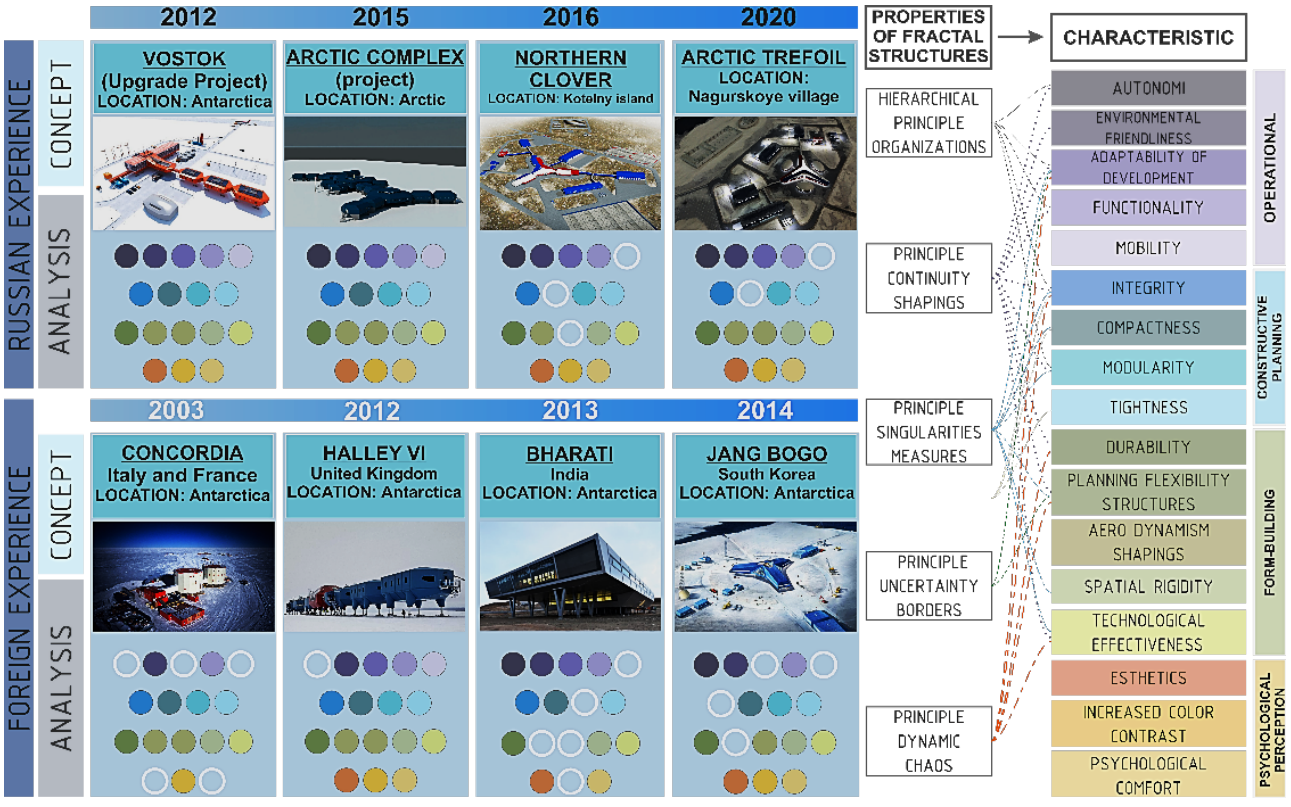

Fig. 4. Influence of fractal systems properties on architectural objects characteristics for severe climatic conditions on the example of research and military stations of 2003-2020.

Above is a correlation table of characteristics significant for architectural objects in harsh climate conditions with the properties of fractal structures. The list of resource characteristics is based on the analysis of existing facilities and on the above-mentioned principles of sustainable design for the Arctic. The characteristics are selected based on their importance for the operation of architectural objects in harsh climatic conditions, while taking into account that the same property can contribute to the provision of different characteristics, including the following in several groups:

Operational Group ${ }^{2}$ :

- Autonomy - the ability of the object to self-sustainment;

- Environmental friendliness - minimal impact on the environment;

- Adaptability of development - the possibility of structural change if necessary and the presence of the life cycle of the building;

- Mobility - object's ability to move.

- Constructive Planning Group:

- Integrity - the presence of closed planning links between parts of the facility is very important for the northern architecture;

- Compactness - space efficiency;

- Modularity - the presence of standardized parts used to create an integrated structure;

- Tightness - the ability of the object to prevent penetration into the internal microclimate of external influences.

- Formbuilding Group ${ }^{3}$ :

${ }^{2}$ This group includes directly those characteristics that have a direct effect on the possibilities and convenience of long-term use.

${ }^{3}$ This group includes characteristics that are directly related to the appearance and engineering and structural component of the architecture. It should be noted that, unlike other groups in which some relaxation to characteristics is permissible, or the absence of some of them, resource characteristics 
- Durability - the ability to maintain long-term operability until the limit state;

- Flexibility of the planning structure - possibility of development and transformation of the facility;

- Aerodynamics of shaping - shape streamlining. Increases the resistance of the structure to strong winds characteristic of the Arctic climate;

- Spatial stiffness - geometric invariability of the object;

- Processability - convenience of production, repairability and operational quality.

- Psychological Perception Group ${ }^{4}$.

- Aestheticity - complex perception of the object in terms of appearance;

- Increased color contrast - light-color solution of the object;

- Psychological comfort - creating conditions for a comfortable life.

Based on the selected characteristics, it can be concluded that using the properties of fractal structures:

Firstly, it has a direct positive effect on almost all groups of resource characteristics significant in design in the Arctic and Antarctica. The exception is only characteristics related to psychological perception, which their influence does not apply to.

Secondly, it makes it possible already at the stage of creating the concept to provide variations in the development of the object as a whole system, which can most efficiently respond to changes in external factors, which allows you to implement the optimal scenario of the life cycle of the architectural object.

\section{References}

1. Peter Horton, Benjamin P. Horton, Re-defining Sustainability: Living in Harmony with Life on Earth, One Earth 1, 1 (2019) DOI:10.1016/j.oneear.2019.08.019

2. N. A. Saprykina, Futurological concepts of the 20th century as an innovative forecast, Electronic journal AMIT (2015)

3. E. N. Knyazeva, S.P. Kurdyumov, The foundations of synergy. Aggravated regimes, self-organization, tempomirs. (Aleteia, St. Petersburg, 2002)

4. I. Prigogine, Philosophy of instability, Questions of philosophy 6 DOI: 10.1016/S00163287(89)80009-6

5. Mehmet Efe Biresselioglu, Muhittin Hakan Demir, Berfu Solak, Altan Kayacan, Sebnem Altinci, Investigating the trends in arctic research: The increasing role of social sciences and humanities, Science of The Total Environment 729, 139027 (2020), DOI: $10.1016 /$ j.scitotenv.2020.139027

6. José Edgardo, Abaya Gomez Jr., The size of cities: A synthesis of multi-disciplinary perspectives on the global megalopolis, Progress in Planning 116 (2017) DOI: 10.1016/j.progress.2016.03.001

7. Melanie Crane, Simon Lloyd, Andy Haines, Ding Ding, Emma Hutchinson, Kristine Belesova, Michael Davies, David Osrin, Nici Zimmermann, Anthony Capon, Paul Wilkinson, Catalina Turcu, Transforming cities for sustainability: A health perspective, Environment International, 147, 106366 (2021) DOI: 10.1016/j.envint.2020.106366

8. Marina Mihaila, City Architecture as Cultural Ingredient, Procedia - Social and Behavioral Sciences, 149 (2014), DOI: 10.1016/j.sbspro.2014.08.211

belonging to this group should be strictly present, as they are the basis for the safe use of architecture in the Arctic and Antarctic.

${ }^{4}$ The resource characteristics included in this group, unlike others, can be determined subjective, since in their case the human factor is most pronounced. However, they should not be neglected. 
9. Decker Julie, Modern North - Architecture on the Frozen Edge (Princeton Architectural Press, New York, 2010)

10. Lola Sheppard, Mason White, Many Norths: Spatial Practice in a Polar Territory, Actar Publishers (2017)

11. Usenyuk-Kravchuk Svetlana, Maria Gostyaeva, Alexandra Raeva, Nikolai Garin, Encountering the extreme environment through tourism: The Arctic design approach, Journal of Destination Marketing \& Management 19 (2021) DOI: 10.1016/j.jdmm.2020.100416

12. Zdeněk Lyčka, Josef Elster, Punk's not dead, even at the Czech Arctic Scientific Station in Svalbard, Oceanologia 62 (2020) DOI: 10.1016/j.oceano.2020.03.007

13. Peter Hemmersam, Arctic Architectures, Polar Record 52 DOI: 10.1017/S003224741500100X

14. M. Emelina, M. Savinov, P. Filin, The Arctic Beyond Science Fiction (Paulsen, 2018)

15. S. B. Pomorov, A.A. Filippov, Fractals and their participation in architectural design Polzunovsky Vestnik 1 (2014)

16. V. N. Babich, On fractal models in architecture [Electronic resource] Architecture: news of universities, 30 (2010) http://archvuz.ru/2010_2/2

17. V. N. Babich, Fractal structures in planning and building of the city The RAASN Academic bulletin, 2 (2009)

18. S. A. Hassan, D.H. Zanette, Stationary structures in a three dimensional reaction diffusion system, Physica A: Statistical Mechanics and its Applications 214, 3 (1995) DOI: 10.1016/0378-4371(94)00281-W

19. Andreas Müller, Perspective Cahier No.1 (Hatje kantz,Germany, 2010

20. Biloria Nimish, From smart to empathic cities, Frontiers of Architectural Research 10, 1 (2021) DOI: 10.1016/j.foar.2020.10.001

21. Swati Apurva, Satish Tailor, Neera Rastogi, Smart Materials for Smart Cities and Sustainable Environment, Journal of Materials Science \& Surface Engineering 5, 1 (2017) DOI: 10.jmsse/2348-8956/5-1.5

22. Iasef MdRiana, Shuichi Asayama, Computational Design of a nature-inspired architectural structure using the concepts of self-similar and random fractals Automation in Construction, 66 (2016) DOI: 10.1016/j.autcon.2016.03.010

23. Iasef MdRiana, Mario Sassone, Shuichi Asayama, From fractal geometry to architecture: Designing a grid-shell-like structure using the Takagi-Landsberg surface, Computer-Aided Design, 98 (2018) DOI: 10.1016/j.cad.2018.01.004

24. Bela Abboushi, Ihab Elzeyadi, Richard Taylor, Margaret Sereno, Fractals in architecture: The visual interest, preference, and mood response to projected fractal light patterns in interior spaces, Journal of Environmental Psychology, 61 (2019) DOI: 10.1016/j.jenvp.2018.12.005

25. Saurav Dixit. Anna Stefańska, Adam Musiuk, Architectural form finding in arboreal supporting structure optimization, Ain Shams Engineering Journal (2020), DOI: 10.1016/j.asej.2020.08.022

26. Lazaros Mavromatidis, Coupling architectural synthesis to applied thermal engineering, constructal thermodynamics and fractal analysis: An original pedagogic method to incorporate "sustainability» into architectural education during the initial conceptual stages, Sustainable Cities and Society, 39 (2018) DOI: 10.1016/j.scs.2018.01.015

27. Ingy Ibrahim El-Darwish, Fractal design in streetscape: Rethinking the visual aesthetics of building elevation composition, Alexandria Engineering Journal, 58, 3 (2019) DOI: 10.1016/j.aej.2019.08.010 